\title{
¿CABE ANTROPOLOGÍA NATURAL, SEGÚN KIERKEGAARD, $O$ SOLO POR FE?
}

Is natural anthropology possible according to Kierkegaard or is it only possible based on faith?

Juan Fernando Sellés*

\section{Resumen}

En este trabajo se estudia si, según Kierkeggard, el conocimiento de la propia intimidad humana es natural o exclusivamente sobrenatural. Se concluye que, aunque tal punto no sea explícito en los textos del pensador danés, ya que admite que la relación del hombre con Dios es en exclusiva sobrenatural, por medio de la fe, y que esta no es cognoscitiva porque acepta que Dios está detrás del absurdo, por consiguiente, según él no cabe antropología filosófica como ciencia.

Palabras clave: Kierkegaard. Conocimiento de sí y de Dios. Antropología filosófica. Fe fiducial.

\section{Abstract}

In this paper, we examine whether knowledge of our own human intimacy is natural or exclusively supernatural, as Kierkegaard proposes. We conclude that, even though this idea is not explicit in his writings, he admits that man's relationship with God is exclusively supernatural through faith, and that faith is not cognitive because it accepts that God is behind the absurd; hence, philosophical anthropology is not possible as a science.

Key words: Kierkegaard. Knowledge of self and God. Philosophical Anthropology. Fiducial faith.

\section{PLANTEAMIENTO: ¿ES EL CONOCIMIENTO DE SÍ NATURAL O SOLO DEBIDO A LA FE?}

A primera vista no parece claro que, para Kierkeggard, el conocimiento propio sea solo de orden sobrenatural: "la conciencia cristiana presupone una interna conciencia humana precedente (y esto tanto en la historia del género humano cuanto en la del singular)" (167). En efecto, se puede defender que, para Kierkeggard, el conocimiento propio es natural, no debido en exclusiva a la ayuda sobrenatural (revelación particular, manifestación de la propia vocación, etcétera). Esta tesis se puede basar en varios argumentos. Por ejemplo, que, según el pensador danés, "la tarea del pensador subjetivo es comprenderse a sí mismo en la existencia" (346), y esto es asequible a todo hombre, no solo al que posee fe sobrenatural.

Que, para Kierkegaard, “conocerse a sí mismo en la existencia es también el principio cristiano" (348); pero si dice 'también', esto indica que no solo el cristiano es 'pensador subjetivo'.

Que, según el pensador de Copenhague, "la interioridad es la relación del individuo consigo mismo ante Dios"(426), pero esto no comporta que esa relación sea en exclusiva de la fe sobrenatural. 
Que, para este escritor religioso, el hombre "en lo más íntimo de su ser... está absolutamente comprometido en su relación con Dios"(494), pero tampoco esto indica que esa religación sea exclusivamente de orden sobrenatural.

Que, para Søren, la religiosidad del paganismo -la natural- permite una profundización interior (es lo que llamó religiosidad del 'tipo A'), mientras que en la del cristianismo -la sobrenatural-apuesta por el absurdo (a la que denominó de 'tipo B'), que él entendió de modo fideísta; por tanto, también los que carecen de fe cristiana acceden a conocer su intimidad.

Que, según él, "el objeto de la fe es la realidad de otra persona"(322); por tanto, no puede ser la propia intimidad; con lo que el conocimiento de esta puede ser natural.

En suma, con los argumentos que preceden, y otros, se puede sostener, a primera vista, que no es claro que la antropología kierkegaardiana sea, en el fondo, un rendimiento debido solo a la fe cristiana que él profesa, es decir, que no es neto en sus textos que Kierkegaard afirme que solo se sabe de la propia intimidad por lo que de ella revela Dios a cada quien. No obstante, las referencias precedentes pertenecen a una de sus obras seudónimas, la más filosófica, el Postscriptum. Pero, como es sabido, por una parte no se consideraba a sí 'filósofo', sino 'escritor religioso'; y, por otra, en el 'Apéndice' final de dicho libro declaró que "en los libros seudónimos no hay ni una sola palabra mía",

Además, debido a la impronta luterana de su fe, en caso de admitir que el conocimiento de la propia intimidad sea también natural, se puede poner en entredicho la validez del mismo, porque, según dicha fe, la naturaleza humana se supone 'enteramente corrupta' y, por tal razón, también estará completamente dañado dicho conocimiento natural: "el paganismo decía: conócete a ti mismo. El cristianismo dice: no, esto no es más que el principio... No hay algún conocimiento verdadero de sí mismo sin el conocimiento de Dios"(72). De modo que en este trabajo nos enfrentamos a la difícil tarea de dilucidar si, para Kierkegaard, es posible conocimiento natural de sí, o por el contrario solo es posible el sobrenatural y, por tanto, sí es posible la antropología filosófica.

\section{1. ¿ES LA RELACIÓN DEL HOMBRE CON DIOS NATURAL O SOBRENATURAL?}

Søren mantuvo que la relación del hombre con Dios es en exclusiva de $f e$ : "Dios es verdaderamente aquel Yo, el Sujeto que, en relación con el hombre, debe acrecentar su Yo, de modo que sea únicamente objeto de fe... Organizará siempre la cosa de tal modo que sea contraria al intelecto"(74). Y, como opuso la fe a la razón, su concepción religiosa devino negativa (Law). En efecto, Kierkegaard es fideísta en su modo de entender la fe sobrenatural, pues admite que el único acceso válido a Dios es el que otorga la fe, que esta se encuentra al margen de la razón, que no es cognoscitiva y que se ciñe en exclusiva a la voluntad.

\footnotetext{
1 'Primera y última declaración', incluida al final del Postscriptum, 604.
} 
Con todo, hay que hacer valer un punto de su fideísmo: la intensidad o fortaleza con que trató de vivir esa fe, pues supeditó toda su fuerza vital a ella; más aún, negó con lo que él denominaba un 'martirio constante' el natural aliento vital por considerarlo contrario a dicha fe. En efecto, frente a la ordinaria manera de vivir la fe por parte de la mayoría de los creyentes, que -según él- estriba en vivir su vida y tener la fe como algo sobreañadido a ella para que esta transcurra de modo pacífico, la fe para Søren era lo superior en su vida y, en consecuencia, sometía a ella todo lo demás. Ese modo de vivir la fe con valentía, con todas sus consecuencias, de modo extraordinario, es más admirable aun cuando esta fe la estimaba sin contenido temático definido, e incluso con temática absurda, paradójica, contradictoria. Por lo demás, Kierkegaard intentó suplir la falta de fondo doctrinal en la fe con el amor divino ${ }^{2}$.

Para Levinas, "la novedad filosófica de Kierkegaard estriba en su noción de creencia" (79). No obstante, es evidente que tal 'creencia', más que filosófica, es religiosa, y más que 'novedad', tenía - desde Ockham- más de cinco siglos de andadura. Se trata de una fe que, tras dejar perplejo, entre otros, a Derrida ${ }^{3}$, este autor la pone en entredicho. Søren negó que el conocer íntimo que el hombre tiene de Dios sea natural, pues postuló que es exclusivamente sobrenatural, ya que afirmó que Dios se revela solo al que ora, ya sea dentro del cristianismo o fuera de él ${ }^{4}$. Pero el que solo se pueda acceder a Dios por medio de la fe, postulado netamente fideísta, no es correcto y, en Søren, debe su fuente a Lutero (el que también influyó en Kant) y, asimismo, a Hamann $^{5}$. En esto, además, Kierkegaard se opuso a Schleiermacher ${ }^{6}$. Por su parte $-\mathrm{y}$ como es sabido- en este punto el Reformador protestante tuvo su inspiración en la propuesta de Ockham. Søren añadió a este planteamiento que Dios se manifiesta más en el cristianismo que fuera de él, admitiendo, por tanto, la jerarquía en la revelación sobrenatural divina. Esto último es correcto y contrario a lo que sostuvo el deísmo.

\footnotetext{
${ }^{2}$ Según Collins, "el verdadero punto de apoyo de Arquímedes (del pensamiento de Søren) no era otro que la fe en el amor paternal de Dios por nosotros" (40). Afirma también que "Kierkegaard sostiene que la existencia de Dios se puede aprehender solo creyendo en ella. Su existencia es cierta para nosotros solo cuando "pasamos por alto la prueba' y damos el salto a la fe, lo que William James llamaba salto mortale" (162); lo que, para este intérprete, no es un caso de fideísmo; pero en esto debemos disentir.

3 “Herético o paradójico, este caballero de la fe, ¿es judío, cristiano o judeo-cristiano-musulmán?" (Derrida, 91).

${ }^{4}$ Nicoletti, en cambio, afirma que "per Kierkegaard solo in Cristianesimo può svelare il misterio dell' esistenza" (11).

${ }^{5}$ Con razón Hamann dice: 'como la ley deroga la gracia, así el comprender deroga el creer'. Es también mi tesis. Pero en Hamann es un aforismo, mientras que yo, a fuerza de luchar, me he librado de toda una cierta filosofia y cultura, hasta sentar la tesis: comprender que no se 'puede' comprender, o bien (el aspecto más ético y piadoso) que no se 'debe' comprender la fe" (Kierkegaard, Diario, 12).

6 "Lutero define la fe de una manera muy justa: dice que es exactamente lo contrario del sentimiento". (Kierkegaard, Diario, 200).
} 


\section{2. ¿DIOS ESTÁ DETRÁS DE LA VERDAD O DEL ABSURDO?}

Sin abordar temas propios de la teología - porque no es ni nuestro cometido ni el de Kierkegaard, en él esta disciplina no cabe como ciencia-, hay que hacer una alusión a ella, pues como la fe cristiana se apoya fundamentalmente en la persona de Cristo, no es indiferente la concepción que se tenga sobre él de cara a la imagen de hombre que se posea, porque en la Revelación cristiana se declara que somos imagen suya, que él es nuestro Camino y Modelo. Pues bien, según Kierkegaard la figura del Dios-hombre equivale a la paradoja: al absurdo ${ }^{7}$.

Søren mantuvo asimismo que la semejanza entre Dios y el hombre consiste, sobre todo, en la desemejanza, es decir, en la completa heterogeneidad", y que "toda la confusión de los tiempos modernos... consiste en haber abolido el inmenso abismo de la diferencia cualitativa entre Dios y el hombre" (Kierkergaard, Diario, 97), afirmación manifestativa de que su concepción de la religión es negativa -en el sentido neoplatónico-. En suma, Cristo es, para Kierkegaard, un misterio, pero no por exceso de luz, sino porque alberga en su seno la contradicción, lo que acarrea oscuridad para la antropología 9 .

Es más, el criterio con el que Søren marca el 'salto' de uno a otro de los estadios jerárquicos de la vida ('estético-ético-religioso') es la contradicción (postulado de neto influjo hegeliano), concebida en su caso desde una perspectiva humana como conflicto interior (Kierkergaard, Diario,155-156). En cambio, según la Iglesia católica, Cristo es, tanto como el Camino y el Modelo, la Verdad; y recuerda además, que "Cristo... manifiesta plenamente el hombre al propio hombre y le descubre la grandeza de su vocación" $" 10$. De manera que el misterio de la Persona de Cristo, de excesiva luz, es un acicate para conocerle más y, por medio de él, para conocerse mejor.

Kierkegaard sostuvo también que "ningún hombre puede alcanzar conocimiento de él (Dios) sin llegar a ser un pecador" (Kierkergaard, Confesión, 397). Y añadió que "nadie puede ver a Dios sin pureza, y el pecado es precisamente impureza, y por eso nadie puede alcanzar conocimiento de Dios sin llegar a ser un pecador" (408, cursivas en el original). Esta afirmación, de neto trasfondo luterano, parece implicar que al margen de la fe (se trata, obviamente, de la cristiana) no es posible el conocimiento de Dios. De acuerdo con esto, parece también que, para Søren, solo quien busca a Dios por

\footnotetext{
7 "Dios está detrás del absurdo" (Kierkegaard, Temor, 42). "En lo absoluto encalla la razón" (Kierkegaard, Ejercitación, 133). Ver al respecto Olivier Cauly, O., "La foi est-elle une paradoxe ou 'une virtu de l'absurde'? 1997.

8 "Entre Dios y un ser humano... hay una diferencia absoluta; por tanto, la relación absoluta de una persona con Dios debe expresar específicamente la diferencia absoluta, y la semejanza directa se vuelve insolencia, vanidosa pretensión, presunción, y demás" (Kierkegaard, Postscriptum, 403). Esta tesis la avala en sus apuntes íntimos: "Hay una infinita y abisal diferencia cualitativa entre Dios y el hombre" (Kierkegaard, Diario, 138).

9 'Para el hombre, la existencia es irracional, es una paradoja. Para Kierkegaard, la paradoja, el contrasentido y la contradicción no es una figura retórica, sino más bien, siguiendo su manera de expresarse, una 'determinación ontológica', que designa la relación entre un espíritu cognoscitivo existente y la verdad eterna” (Höffding, 89).

${ }^{10}$ Concilio Vaticano II, Constitución pastoral Gaudium et Spes, N. 22. 2. Y en otro lugar se declara: "Cristo sabe lo que hay dentro del hombre. ¡Solo Él lo sabe!”, Christifideles Laici, N. 34, 5.
} 
medio de la fe se conoce a sí mismo, porque en tal caso "buscar significa que el que busca, él mismo se transforma. No es preciso que halle el lugar en el que está lo buscado (Dios), pues está junto a él... es preciso que se transforme para llegar a ser él mismo el lugar en el que Dios verdaderamente está" (404).

Si solo por medio del pecado uno se conoce en relación con Dios, cabría pensar que, para ser más consciente de esa vinculación y del propio sentido personal, habría que acrecentar la vida de pecado -como Lutero sugiere-, pero Kierkegaard matiza que "no se trata de acrecentar la culpa para que Dios se vuelva más grande, pero sí de acrecentar el conocimiento de la culpa" (Kierkergaard, Dieciocho, 409), asunto que es correcto.

En el escrito 'Todo buen don y toda dádiva perfecta viene de arriba' incluido en Dieciocho discursos edificantes, Søren declara que los males (los físicos en los vegetales y animales) también provienen del pecado, pues antes del pecado de Adán todo era 'bueno' y 'muy bueno'. El mal viene de la 'ciencia' humana. El hombre la anhela, pero no hay que encomiarla (144). Como se ve, Kierkegaard parte de la hipótesis luterana de que la naturaleza humana, más que 'herida', está 'corrupta'. A ello añade que el 'pecado original', que provocó tal corrupción, fue un pecado de 'ciencia'.

También Tomás de Aquino sostuvo que tal pecado fuese de 'ciencia' ${ }^{11}$, pero la interpretación del dominico dista mucho de la del danés, porque para el primero significa que, como todo lo que Dios había creado era 'bueno', para introducir el mal en el mundo, el hombre debía manipular, distorsionar, su propio modo natural de conocer, y empezar así a considerar la creación como 'no buena', o que él era capaz de dotar a lo real de un orden mejor que el otorgado por Dios. En el fondo, esta actitud suponía un falseamiento del conocer racional humano, es decir, del hábito adquirido de ciencia por medio del cual conocemos la realidad intramundana y su orden. Esta actitud suponía implícitamente, a la par, admitir que Dios había creado mal, de modo deficiente, lo que equivale a una blasfemia. En suma, el primer hombre trastocó su propio conocer natural. Por tanto, según el de Aquino, el pecado original, más que residir en el conocer natural humano, radicó en su distorsión.

En cambio, para Søren el mal radica simplemente en conocer, en todo tipo de conocer racional, y no solo en el conocer que la persona humana doblega para que este sirva a sus propios intereses. El bien, en cambio, radica en creer al margen y en contra del conocer. Por eso afirma que, tras el pecado de origen, "el hombre, incluso el más amoroso, causa el mal. Si el hombre, que es lo más perfecto de todo, es malo, entonces toda la vida terrena yace en el mal" (Kierkergaard, Dieciocho, 145). Sin embargo, esta tesis no es correcta ni filosófica ni teológicamente tomada.

En efecto, filosóficamente tomada la precedente tesis no es correcta, porque si la naturaleza humana estuviese enteramente corrupta, como esa afirmación es fruto del pensamiento humano, también ella sería falsa. Además, de ser cierta la tesis de que la naturaleza humana está corrompida, el hombre no podría crecer ni cognoscitivamente, por medio de los hábitos intelectuales, ni volitivamente, según las virtudes de la

\footnotetext{
${ }^{11}$ Ver Tomás de Aquino, In II Sent., d. 32, q. 9.
} 


\section{Juan Fernando Sellés}

voluntad, perfecciones de las dos facultades superiores humanas, crecimiento que es palmario. Teológicamente tomada tal afirmación tampoco es correcta, porque no forma parte del depósito de la Revelación: no se encuentra ni en la Sagrada Escritura, ni en la Tradición, ni en el Magisterio eclesiástico. Con todo, hay algo positivo en la concepción kierkegaardiana del mal, y es que -frente a la concepción de Lutero y a la del idealismo alemán (sobre todo Hegel)- lo atribuye en exclusiva al hombre, no a Dios.

Como se advierte, aunque Kierkegaard no niegue de plano que el hombre disponga de un conocer natural que le permita alcanzar a conocer su intimidad, sin embargo, su tesis 'religiosa' de fondo pone en tela de juicio la validez de dicho conocer, el que es condición de posibilidad de la antropología filosófica. Además, entiende tal 'religión' de modo peculiar, porque más que teórica, la considera práctica, subjetiva, individual, incomunicable, como la misma fe que defiende ${ }^{12}$. En consecuencia, como pone a la antropología en dependencia de esa concepción teológica, una tendrá las mismas notas que la otra. Pero, con esas características, ¿será susceptible la antropología de ser considerada como ciencia?

Según la precedente hipótesis, si los hombres son malos por naturaleza, requerirán necesariamente de la ayuda divina. Por tanto, todo bien vendrá de arriba, pero no de modo natural, sino de manera exclusivamente sobrenatural. Es evidente que el bien es Dios (147). Por tanto, si se busca el propio conocimiento, este no se podrá encomendar a las propias fuerzas no éticas humanas, porque se suponen corruptas, falseadas. En consecuencia, el único saber acerca del sentido personal propio será el de la iluminación sobrenatural divina: "frente a Dios siempre hablo con inseguridad sobre mí mismo, pues, en efecto, Él es el único que sabe con seguridad de mi relación con él" (Kierkergaard, Postscriptum, 180). Pero como esa relación no se estima natural, sino en exclusiva don divino otorgado por la $f e$, se puede postular que, para Søren, solo mediante la fe cabrá antropología de la intimidad.

\section{3. ¿LA PERSONA ES CONOCER O TIENE CONOCER?}

En el apartado anterior se ha preguntado si el conocer que nos permite saber que somos una persona es natural o solo sobrenatural. Si es natural, será un instrumento de la persona, no la persona. Respecto de tal conocer habría que averiguar si es nativo o adquirido. Pero ahora conviene averiguar si la persona que somos es conocer o solo tiene conocer. Si la persona es conocer se puede hablar de 'conocer trascendental', es decir, que tal conocer será una perfección pura que caracteriza a toda persona; si, en cambio, tiene conocer, este será un instrumento nativo o adquirido de la persona, pero no la persona.

\footnotetext{
12 "Si alguien piensa que tiene fe, pero es indiferente respecto de esta posesión, ni frío ni calor, entonces puede estar seguro de que tampoco tiene fe. Si alguien piensa que es cristiano y, sin embargo, le es indiferente serlo, entonces la verdad es que tampoco lo es. ¿O qué diríamos de un ser humano que asegurara estar enamorado, y añadiera que esto le es indiferente" (Kierkergaard, Dieciocho, 46).
} 
Es indudable que Kierkegaard habla del 'conocimiento subjetivo' mediante el cual nos conocemos. Independientemente de que este lo entienda como natural o exclusivamente sobrenatural, este conocer no lo entiende como un trascendental personal, es decir, no es la persona como ser cognoscente. Es un conocer de la persona, no la persona como conocer. Que el conocer personal sea trascendental significa que una de las dimensiones radicales nativas de la persona humana es conocer, es decir, que la persona es un conocer activo, un intelecto activo (equivalente a la noción aristotélica de intelecto agente, el que después activará a la razón, intelecto pasivo, lo potencial).

Además, si se toma el conocer personal como método noético, hay que decir que su tema será Dios, porque una persona creada, como 'relación personal' que es, solo puede decir relación personal nativa al Dios personal. Ahora bien, a nivel de intimidad personal Søren habla de la fe sobrenatural, no de un conocer natural abierto a Dios. Estima también que tal fe no es cognoscitiva. Sin embargo, si se admite que la persona humana es un conocer personal, este conocer será afín a lo que se podría llamar 'fe natural', es decir, ese conocer que, más que esclarecer o patentizar su tema (como hace la razón), es una constante búsqueda respecto de él, porque su tema propio, Dios, desborda con creces la capacidad de dicho conocer. Ahora bien, no por ello hay que identificar dicho conocer natural con la fe sobrenatural, y esto sin menoscabo de que tal fe sobrenatural -don divino (no una perfección no ética natural humana nativa o adquirida)- pueda ser la elevación de dicho conocer natural. Pero Kierkegaard no considera este extremo.

En efecto, para Søren lo neurálgico de la intimidad humana es la pasión, no el conocer. Si la fe sobrenatural incide -según él- en la intimidad humana, esta no podrá ser entendida por Kierkegaard así como era entendida por la teología medieval, a saber, como 'un nuevo modo de conocer personal', sino, ante todo, como una pasión, la que -lejos de ser concebida como cognoscitiva-, es interpretada como aceptación de lo absurdo ${ }^{13}$. Ahora bien, esta fe no puede ser 'verdadera' fe porque es contradictoria. Por lo demás, si la fe se entiende como 'paradójica' hasta el 'absurdo', no debe llamar la atención que algunos existencialistas posteriores la hayan abandonado o denigrado. Quien siembra vientos, cosecha tempestades...

Como es sabido, el cristianismo afirma que la fe es un don sobrenatural. Si Søren mantiene que es mediante la 'sola fides' por lo que alcanzamos a Dios. Además de negar la apertura natural de todo hombre a Dios y reservarla únicamente a quien tenga $f e$, sostiene que esa fe no es cognoscitiva. En consecuencia, sobra preguntar qué conocemos de Dios con tal fe, porque la respuesta no puede ser sino nada. Como se ve,

\footnotetext{
13 " Creer con la inteligencia no puede hacerse en modo alguno... La fe tiene dos tareas: estar atenta y descubrir a cada instante la inverosimilitud, la paradoja, para atraparla entonces con la pasión de la interioridad. Por lo general, uno se figura que lo inverosímil, la paradoja, es algo con lo que la fe solo se relaciona padeciéndolo, que debe contentarse provisionalmente con esta relación y que poco a poco esta llega a mejorar bastante, que es incluso verosímil, ¡Qué magnífica confusión hablar así de la fe!... La fe se relaciona automáticamente con lo inverosímil y con la paradoja" (Kierkergaaard, Postscriptum, 233).
} 
admitir que la fe sea un método "quia absurdum"14 de acceso a Dios, tiene consecuentemente como tema un Dios enteramente desconocido cuando no absurdo.

Si Søren supone que la fe que Dios nos da no es luz, conocer, con ella no podemos conocer a Dios. Si no lo conocemos, ¿cómo vamos a saber lo que él quiere de nosotros, es decir, qué revela de nuestra intimidad? De modo que lo que Kierkegaard deseaba ardientemente en su vida práctica, saber qué quería Dios de él, está en contradicción con su formulación teórica de la fe. El planteamiento de su propuesta respecto de la fe se puede resumir como sigue: por una parte, un método -la fe- sin luz $\mathrm{y}$, por otra, un tema -la intimidad divina- incognoscible. Pero este planteamiento da como balance también una oscuridad antropológica.

En efecto, la visión kierkegaardiana del hombre depende de su concepción fiducial protestante. Su propuesta es netamente kantiana (recuérdese: "tuve que poner límites a la razón para dar paso a la fe"15), pero en la base de ambas posiciones está Lutero y, en la de este, Ockham. Efectivamente, por una parte, Søren estima que la naturaleza humana está corrupta; por otra, que la fe sobrenatural que Dios otorga no es cognoscitiva. Por tanto, no ponemos conocer al hombre ni de modo natural ni con la ayuda sobrenatural. En suma, la antropología, y también la teología, no podrán escapar de un agnosticismo de fondo, pues, por un lado, el ser divino será incognoscible (Rae) $\mathrm{y}$, por otro, el yo vendrá a ser una $\mathrm{X}$, una incógnita indespejable.

En definitiva, se puede decir que la antropología de Kierkegaard es teocéntrica (Angeli, 258), porque sabe -como Julius Müller, de quien lo tomó-, que "creando al hombre, Dios teomorfiza" (Kierkergaard, Diario, 111). No defiende explícitamente que solo nos conozcamos por revelación divina, pues no es explícito en sus textos que el método noético que emplea, el 'conocimiento subjetivo', sea en exclusiva de orden sobrenatural. Sin embargo, es cierta su afirmación de que conocerse enteramente como un yo no es posible sino ante y con la ayuda de Dios. Añádase que su concepción de la $f e$ es fideísta, pues admite que el único método de acceso al ser divino es por $f e$ sobrenatural. Ahora bien, como por dicha fe admite que la naturaleza humana está enteramente corrupta, esta tesis conlleva a poner en tela de juicio la validez del conocimiento natural de sí. A la par, como tal fe no es cognoscente, no puede afirmar en coherencia que con ella se alcance a conocer mejor al ser divino. Si no lo conocemos, por consiguiente tampoco podemos afirmar que Dios se nos revele, y que en esa revelación nos manifieste quiénes somos.

\section{A MODO DE CONCLUSIÓN}

A Søren, más que importarle si el hombre conoce su intimidad naturalmente, y si puede acceder naturalmente a Dios desde ella, lo que le interesaba era defender que al ser divino se accede por medio de la fe, que ese acceso es sobrenatural, y que solo por

\footnotetext{
14 “El absurdo es precisamente, a través del rechazo objetivo, el dinamómetro de la fe en la interioridad”, 212.

${ }^{15}$ Prefacio a la $2^{\mathrm{a}}$ ed. de Crítica de la razón pura, 1887 , final.
} 
revelación divina conocemos nuestra intimidad, nuestra vocación. Con esa actitud se puede entender mejor la frase del final del Postscriptum en la que declara que "en los libros seudónimos no hay ni una sola palabra mía", pues si en ellos se habla de filosofia, al prescindir de la filosofia y refugiarse es la 'sola fides', se puede colegir que a Kierkegaard no le importaba el acceso natural humano al ser divino, sino solo el de la $f e$.

Además, si Kierkegaard no considera innato al 'conocer subjetivo', sino adquirido, tampoco tiene por qué importarle que la persona humana sea nativamente una verdad o sentido activo, es decir, un conocer personal. De modo que no puede admitir que tal conocer sea un 'trascendental' nativo en la intimidad personal humana. Añádase que, si Kierkegaard estima que la fe sobrenatural, don divino, es contraria al conocer $^{16}$, la fe no puede ser la elevación del conocer personal nativo. De modo que en su propuesta tenemos dos imposibilidades: una, que la antropología trascendental, la que mira a la intimidad humana (no a las manifestaciones), sea ciencia natural; otra, que teología natural, la que advierte a Dios como ser personal desde la intimidad personal humana, sea asimismo ciencia natural.

Con lo que precede se comprende por qué Søren se dedicó, por una parte, a describir, más que la intimidad personal, las manifestaciones de la existencia humana, asunto que le otorga la paternidad del existencialismo; y, por otra, a vincular la fe con la voluntad, la pasión y la libertad como 'métodos' de acceso a Dios, y con lo paradójico, contradictorio y absurdo como 'temas' divinos.

\section{Universidad de Navarra* \\ Departamento de Filosofia \\ 31080, Pamplona, Navarra (España) \\ jfselles@unav.es}

\section{OBRAS CITADAS}

Angeli, F., L'itinerario di un cristiano nella cristianità. La testimonanza di Kierkegaard, Milano, Italia, 2004.

Cauly, Olivier. La foi est-elle un paradoxe ou «une vertu de l'absurde»? À propos d'une critique de Magnus Eiriksson (Theophilus Nicolaus). In: Kairos 10 (1997): 99-114.

Collins, James. El pensamiento de Kierkegaard, México: F.C.E., 1958.

Derrida, Jacques. "A quien dar (saber no saber)", en AA.VV., Kierkegaard vivo. Una reconsideración, Madrid: Encuentro, 2005.

Höffding, Harald. Søren Kierkegaard, ed. de Vela, F., Madrid: Revista de Occidente, $2^{\mathrm{a}}$ ed., 1949.

Kierkegaard, Søren. "En ocasión de una confesión", en Tres discursos sobre circunstancias supuestas, Madrid: Trotta, 2010.

\footnotetext{
16 “La fe, sensu strictissimo... está referida a la existencia” (Kierkegaard, Postscriptum, 212).
} 
— Dieciocho discursos edificantes, Madrid: Trotta, 2010.

_ Postscriptum definitivo y no cientifico a las 'Migajas filosóficas', Salamanca: Sígueme, 2010.

_ Diario (1839) ed. de C. Fabro, Brescia, Morcelliana, vol. 2 (1980).

— Temor y temblor, ed. de V. Simón Merchan, Madrid, Editora Nacional, 1975.

Law, David.R. Kierkegaard as a negative theologian, Oxford: Clarendon Press, 1993.

Levinas, Emmanuel. "Existencia y ética", en J. P. Sartre et al., Kierkegaard vivo. Una reconsideración, Madrid: Encuentro, 2005.

Nicoletti, Michele. La dialettica dell'Incarnazione: soggettività e storia nel pensiero di Søren Kierkegaard, Bologna: Centro Editoriale Dehoniano, 1983.

Rae, Murray. Kierkegaard and theology, London, New York: T\&T Clark, 2010. 